\title{
An Examination of the Psychometric Properties of Brazilian Portuguese Translations of the Drive for Muscularity Scale, the Swansea Muscularity Attitudes Questionnaire, and the Masculine Body Ideal Distress Scale
}

\author{
Angela Nogueira Neves Betanho Campana \\ and Maria da Consolação Gomes \\ Cunha Fernandes Tavares \\ University of Campinas, Campinas, Brazil
}

\author{
Viren Swami \\ University of Westminster, London, United Kingdom, and \\ HELP University College, Malaysia
}

\author{
Dirceu da Silva \\ University of Campinas, Campinas, Brazil
}

\begin{abstract}
The aim of this study was to translate into Brazilian Portuguese three scales for the assessment of men's body image, namely the Drive for Muscularity Scale (DMS), the Swansea Muscularity Attitudes Questionnaire (SMAQ), and the Male Body Ideal Distress Scale (MBIDS), and to evaluate the factor structure of each of these translated scales. A sample of 878 men completed translated versions of each of the scales, a previously translated Portuguese version of the Body Appreciation Scale, and demographic measures. Confirmatory factor analysis, using unweighted least square estimation and listwise deletion, was used to determine the scales' factorial structures. Results showed that the Portuguese DMS and MBIDS had similar factor structures as their parent versions, whereas the SMAQ had a three-factor structure that diverged from its parent scale. Adequate internal reliability coefficients and evidence of construct validity was established for all three scales. These translated scales provide useful tools for quantitative investigations of men's body image in the Brazilian context and expand the possibility of future cross-cultural research.
\end{abstract}

Keywords: men's body image, drive for muscularity, muscularity attitudes, body ideal distress, Brazil

Prior to the mid-1990s, research on men's body image was primarily focused on recognizing body image disturbance and body dissatisfaction, where these were typically operationalized through discrepancies between current and ideal body size (Fallon \& Rozin, 1985; Thompson, 1990). From this perspective, men were described as more satisfied and relatively free from body image concerns, as compared with women (McCreary, 2011). In fact, men showed less dissatisfaction with body fat than women (Latner \& Wilson, 2011) and some overweight men even declared

This article was published Online First December 03, 2012.

Angela Nogueira Neves Betanho Campana and Maria da Consolação Gomes Cunha Fernandes Tavares, Department of Physical Education, University of Campinas, Campinas, Brazil; Viren Swami, Department of Psychology, University of Westminster, London, United Kingdom and Department of Psychology, HELP University College, Malaysia; Dirceu da Silva, Department of Education, University of Campinas, Campinas, Brazil.

We are grateful to Profs. Don McCreary, Stephen Edwards, and James Mahalik for allowing us to adapt their scales. We also want to thank for CNPq and CAPES for its financial support.

Correspondence concerning this article should be addressed to Angela Nogueira Neves Betanho Campana, Body Image Laboratory, School of Physical Education, University of Campinas - UNICAMP, 701 Érico Veríssimo Avenue, ZIP 13083-851, Campinas, SP, Brazil. E-mail: angelanneves@yahoo.com.br being comfortable with their own weight (Luciano, 2001; Mickalide, 1990). More recently, however, researchers have assessed a specific social standard for men's physical attractiveness, namely their muscularity (McCreary, 2011). Thus, recent work has highlighted the importance of muscularity in understanding men's corporeal experiences (Thompson \& Cafri, 2007) and their behaviors related to muscular ideals (Pope et al., 2005) as well as adiposity (Gray \& Ginsberg, 2007; Ridgeway \& Tylka, 2005; Stanford \& McCabe, 2000; Vartanian, Giant, \& Passino, 2001). It should be noted, however, that muscularity and adiposity components are not equally salient, and self-ideal discrepancies on the muscularity dimension has been more consistently shown to be associated with adverse outcomes than the adiposity component in men (McCreary, 2011).

Men's drive for muscularity refers to their desire to achieve an ideal muscular body, as well the degree of concern that an individual can have about increasing muscle mass (McCreary, 2007; McCreary \& Sasse, 2000; Morrison, Morrison, \& McCann, 2006). To the extent that many cultures idealize lean and mesomorphic aesthetical ideals for men (Swami \& Tovée, 2005), the drive for muscularity also reflects a desire to comply with these ideals of male physical attractiveness (McCreary, Sasse, Saucier, \& Dorsch, 2004). These are important public health concerns because high levels of drive for muscularity are associated with low self-esteem, greater incidence of depression, greater social physique anxiety, negative affect, abuse of anabolic steroids, and exercise dependence (Cafri, Strauss, \& Thomp- 
son, 2002; Chittester \& Hausenblas, 2009; McCreary, 2011; Olivardia, 2001).

In order to more accurately measure men's body image concerns and thereby gain a better understanding of areas requiring intervention, it is essential for scholars to develop and use psychometrically sound scales. To date, several distinct scales have been created to evaluate drive for muscularity among men, including the Male Body Attitudes Scale (MBAS; Tylka, Bergeron, \& Schuartz, 2005), the Drive for Muscularity Attitudes Questionnaire (DMAQ; Morrison, Morrison, Hopkins, \& Rowan, 2004), the Swansea Muscularity Attitudes Questionnaire (SMAQ; Edwards \& Launder, 2000), and the Drive for Muscularity Scale (DMS; McCreary \& Sasse, 2000).

Although there has been some criticism of its development and factor structure (Morrison, Morrison, \& McCann, 2006), the DMS is the most frequently used scale to measure drive for muscularity, having better indices of reliability and validity than the other afore-mentioned scales (Cafri \& Thompson, 2004, 2007; Wojtowicz \& von Ranson, 2006). Among men, the DMS has been shown to consist of two factors, called muscularity-oriented body image and muscularity-oriented behaviors (McCreary, 2011). However, given that both lower-order factors also load on a single higherorder DMS factor (McCreary et al., 2004), researchers have also used a total DMS score for men (Davis, Karvinen, \& McCreary, 2005; Karazsia, \& Crowther, 2009; Swami \& Voracek, in press), which is consistent with the finding that the scale has a onedimensional factor structure among women. Both subscale and total scores have very good internal consistency coefficients and patterns of concurrent, convergent, and discriminant validities (Bergeron \& Tylka, 2007; Chittester \& Hausenblas, 2009; Karazsia, \& Crowther, 2009; McCreary, 2007; McCreary \& Saucier, 2009; Nowell \& Ricciardelli, 2008).

Despite its popularity, however, only a few studies have explored the psychometric properties of the DMS in North America, and these studies have typically relied on university and college samples (McCreary \& Sasse, 2000; McCreary et al., 2004; Litt \& Dodge, 2008). Outside North America, the DMS has been translated into Mexican Spanish and has been validated for men and women (Escoto, Alvarez, Franco, Camacho, \& Mancilla, 2010). The Spanish version of the DMS has been suggested to consist of three subscales, namely muscle-oriented body image, use of dietary supplements, and training obsessiveness (Ruiz, de Leon, Garrido, \& Castillo, 2010). Additionally, an alternative two-factor structure for physically active people involved in a predominantly aerobic sport has been verified among Scottish men (McPherson, McCarthy, McCreary, \& McMillan, 2010).

In turn, the 20-item SMAQ allows researchers to evaluate the desire for greater muscularity, the predisposition to engage in muscularity building-actives, and the benefits of being muscular in terms of physical attractiveness, confidence, and masculinity reaffirmation (Edwards \& Launder, 2000). The SMAQ has mainly been criticized for being repetitive (Hatoum \& Belle, 2004; Morrison \& Morrison, 2006) and studies have also variously adopted a 5-point response scale (Morrison \& Morrison, 2006) or the original 7-point scale (Wojtowicz \& von Ranson, 2006). Although a three-factor structure has been proposed for the SMAQ (consisting of intention to become more muscular, positive attributes of muscularity, and engagement in muscle-building activities; Morrison \& Morisson, 2006), the original two-factor structure (con- sisting of desire to be more muscular and the perceived consequences of being muscular) is more commonly used (Tylka, Bergeron, \& Schwartz, 2005; Wojtowicz \& von Ranson, 2006).

Even so, there are very few studies assessing the psychometric properties of the SMAQ in non-Western cultures. Jung, Forbes, and Chan (2010) reported that the two-factor SMAQ had adequate internal consistency coefficients among a sample of college men in Hong Kong, although they delivered the scale in its original English version. Two studies appear to have used Chinese versions of the SMAQ (Liao et al., 2010a, 2010b), although the authors computed overall scores of all items, rather than subscale scores, making interstudy comparisons difficult. As with the DMS, then, there is a need for more careful assessments of the psychometric properties of the SMAQ outside North America.

Because drive for muscularity is not just about achieving a muscular body, but also the expression of how much an individual internalizes the mesomorphic bodily ideal (McCreary, 2007; McCreary \& Sasse, 2000), it is useful to assess how much being distant from the muscular ideal body could cause distress in a person. That is, although the hegemonic ideal is a mesomorphic body, the degree to which each individual will adopt this ideal is personal and variable (Ryan \& Morrison, 2009). From this perspective, what is important is not simply the distance from one's ideal, but rather how this perceived distance impacts upon the individual in terms of negative behaviors adopted to achieve the ideal body, such as the use of anabolic steroid use (Kimmel \& Mahalik, 2004). To assess this aspect of men's body image, Kimmel and Mahalik (2004) developed the 8-item Masculine Body Ideal Distress Scale (MBIDS) to assess the distress caused among men as a result of having excessive adiposity and lack of muscle definition. Although this measure has a one-dimensional factor structure, its psychometric properties have previously not been examined outside North America.

In the present study, we sought to add to the growing body of literature examining men's body image by developing Brazilian Portuguese translations of the DMS, SMAQ, and MBIDS. These three scales were selected because they allowed us to concurrently examine different aspects of drive for muscularity. More specifically, DMS items are focused on behavioral components and attitudes regarding the concern of not being muscular enough and the desire to be more muscular. The SMAQ does not have items about muscular behaviors, but rather explores different aspects of muscular attitudes, such as the negative feelings associated with lower levels of muscularity, belief in positive value of muscularity, and the predisposition to invest in a muscular body. Finally, the MBIDS assesses a distinct aspect of drive for muscularity, focused on the emotional impact caused by not achieving the ideal, muscular body. Taken together, these three scales provide researchers with a comprehensive view of drive for muscularity, as recommend by Thompson (2004), providing information about behavior and different attitudes (cognitive and emotional) that are present in drive for muscularity.

In terms of the present study specifically, the Brazilian context is useful for examining issues related to men's body image for a number of reasons. First, it has been suggested that Brazil is experiencing a "cult of the body" that places extreme importance on a well-shaped body figure for both women and men (Goldenberg, 2002), alongside a normalization of body modification strategies and behaviors (Dorneles de Andrade, 2010; Edmonds, 2007). 
For example, compared to North America and Europe, where women are more likely than men to consider having cosmetic surgery, a recent Brazilian study indicated few sex differences on this measure (Swami et al., 2011), which was argued to reflect the importance placed on male physical appearance in Brazil.

Indeed, male physical appearance seems to be highly valued in Brazil, both as an aesthetic ideal and as a symbol of social status and ascent (Goldenberg, 2002). For example, Sabino (2000) has discussed the importance of muscularity as a symbol of male identity and masculinity, possibly affording Brazilian men a means of emphasizing gendered differences and maintaining patriarchal domination in a context marked by increasing gender equality (cf. Swami \& Voracek, in press). Certainly, the hypermesomorphic body appears to be highly idealized by Brazilian men, both in order to establish respect among peers and to attract prospective partners (Iriart, Chaves, \& Orleans, 2009). Moreover, the available data shows that about a fifth of gym clients in São Paulo, the richest Brazilian city, regularly use anabolic steroids as a means of attaining a muscular ideal (Silva \& Moreau, 2003).

To date, however, Brazilian researchers have not evaluated male body image with appropriate, psychometrically sound scales and, where appearance concerns have been the focus of research, scholars have typically failed to measure core components of men's body image: muscular appearance, upper body parts, and exercise and eating attitudes (Cafri \& Thompson, 2004; Campana \& Tavares, 2009). Indeed, the lack of psychometrically sound scales to evaluate drive for muscularity in the Brazilian context appears to have resulted in a heavy focus on qualitative research at the expense of more systematic quantitative studies (Campana \& Tavares, 2009).

\section{Method}

\section{Participants}

The participants of this study consisted of 878 men, recruited from among the Brazilian army $(n=254,28.9 \%)$; university students from private $(n=25,2.8 \%)$ and public universities $(n=$ $63,7.2 \%)$; employees from a multinational industrial firm $(n=66$, $7.5 \%$ ) based in the city of Campinas (São Paulo State); athletes and gym users $(n=62,7.1 \%)$; and nonmilitary candidates for a temporary position in the Brazilian army $(n=408,46.5 \%)$. Data were collected in several cities in the states of São Paulo, Minas Gerais, and Rio de Janeiro. This particular strategy was adopted in order attain a more representative sample of Brazilian men than would be obtained through reliance on university students alone. Participants ranged in age from 18 to 39 years (mean $[M]=20.90$, standard deviation $[S D]=4.74)$ and had a mean self-reported body mass index (BMI) of $23.53 \mathrm{~kg} / \mathrm{m}^{2}(S D=3.17)$. The majority of participants described themselves as single $(49.2 \%)$ or in a romantic relationship (40.3\%), 9.9\% were married, and $0.6 \%$ were divorced. In terms of educational qualifications, $15.4 \%$ had completed primary education, $51.7 \%$ had completed secondary education, $29.1 \%$ had an undergraduate degree, and $3.8 \%$ had a further degree or specialist diploma.

\section{Materials}

Drive for Muscularity Scale (DMS; McCreary \& Sasse, 2000). The 15-item DMS was developed as a measure of the desire to be more muscular. Items were rated on a 6-point Likert-type scale $(1=$ always, $6=$ never $)$ and all items were reverse-coded prior to analyses. McCreary et al. (2004) proposed a two-factor solution, consisting of muscularity-oriented body image (items 1, 7, 9, 13, 14 , and $15 ; \alpha=.88$ ) and muscularity-oriented behavior (items 2 , $3,4,5,6,8$, and $12 ; \alpha=.81$ ). McCreary et al. (2004) also found that item 10 , referring to the use of anabolic steroids, failed to load on either factor, although more recently McPherson et al. (2010) indicated that it adequately loaded onto the second factor.

Swansea Muscularity Attitudes Questionaire (SMAQ; Edwards \& Launder, 2000). The 20-item SMAQ was developed to evaluate men's muscularity concerns and attitudes. Items were rated on a 7-point scale, Likert-type scale $(1=$ absolutely agree, 7 = absolutely disagree), which was the originally developed response format. Edwards and Launder (2000) proposed a twofactor solution, which assessed drive for muscularity (10 items) and positive attributes of muscularity (10 items). The authors also found a high internal reliability value for each of these factors $(\alpha=.94$ and .91 , respectively).

Masculine Body Ideal Distress Scale (MBIDS; Kimmel \& Mahalick, 2004). The MBIDS was developed to evaluate the level of distress associated with failing to achieve an ideal muscular body. Items were rated on a 4-point Likert-type scale $(1=$ not distressing at all, $4=$ very distressing). Exploratory factor analysis showed that the scale is unifactorial. Cronbach's alpha test value for MBIDS was .89 (Kimmel \& Mahalik, 2004).

Body Appreciation Scale (BAS; Avalos, Tylka, \& WoodBarcalow, 2005; Brazilian Portuguese translation: Swami et al, 2011). The 13-item BAS was designed as a measure of positive body image, where items are rated on a 5-point Likert-type scale $(1=$ never, $5=$ always $)$. Although the BAS has a one-dimensional factor structure among Western samples (Avalos et al., 2005; Swami, Stieger, Haubner, \& Voracek, 2008), the Brazilian Portuguese version of the scale reduces to two factors measuring general body appreciation (10 items) and body image investment (three items), which mirrors findings in other non-Western settings (Swami \& Chamorro-Premuzic, 2008; Swami, Hwang, \& Jung, 2012; Swami \& Jaafar, in press). For the present purposes, we only used the Portuguese General Body Appreciation subscale, which has been shown to have adequate psychometric properties (Swami et al., 2011). Cronbach's alpha for this scale in the present study was .87 . The BAS was specially included in this study to allow for an evaluation of the MBIDS' discriminant validity.

Demographics. Participants self-reported their demographic information, namely age, highest educational qualification, height, and weight. The latter two variables were used to calculate participants' self-reported BMI $\left(\mathrm{kg} / \mathrm{m}^{2}\right)$. In addition, participants completed the Kasaris Fit Index Scale (Heyward \& Stolarczyk, 1996), in which participants are asked to self-report their physical activity practices in terms of frequency $(1=<$ once a month, $5=$ $>6$ times per week $)$, intensity $(1=$ Light aerobic exercise, $5=$ High intensity activities $)$, and duration $(1=<10$ minutes per session, $5=>30$ minutes per session).

\section{Scale Translation}

Brazilian Portuguese versions of the DMS, SMAQ, and MBIDS were prepared following the guidelines of Beaton, Bombardier, Guillemin, and Ferraz (2002). First, the scales were independently 
translated into Brazilian Portuguese by two native Portuguese speakers, and two different translations $\left(\mathrm{T}_{1}\right.$ and $\left.\mathrm{T}_{2}\right)$ were created. Second, a synthesis version $\left(\mathrm{T}_{12}\right)$ was drawn up by the two translators and a neutral judge. Third, from the synthesis, two back-translations $\left(\mathrm{BT}_{1}\right.$ and $\mathrm{BT}_{2}$ ) were created by two translators (English-speaking natives with Brazilian Portuguese proficiency) who had no knowledge of the original instruments or aspects of body image. Fourth, all the versions $\left(\mathrm{T}_{1}, \mathrm{~T}_{2}, \mathrm{~T}_{12}, \mathrm{BT}_{1}, \mathrm{BT}_{2}\right)$ were forwarded to an expert committee, consisting of the two translators, the two back-translators, the synthesis judge, a psychoanalyst, a methodologist, and a linguist. This committee examined the versions of each questionnaire and discussed the items to ensure a clear pretest version, equivalent to the original in terms of semantics, language, culture, and concept (Herdman, Fox-Rushby, \& Badia, 1998).

These pretest translations were then presented to 15 participants (age range 18-39 years) recruited from the University of Campinas. Each participant completed the pretest scales and, following this, took part in an interview to verify item and instruction comprehensibility, lay-out adequacy, and congruence between desired answer and indicated answer (which was especially important for negative items and situations of double negatives). The pretest indicated a need for revisions on three items of the SMAQ (items 2,11, and 18). The clarity of these items was considered poor, since participants related some difficulty in interpretation and answer provision. The expert committee then met again to discuss those three items. Following further revisions, a new pretest with six volunteers (age range 19-39 years) was conducted, following the same procedures of the first pretest. This second pretest indicated that there were no further problems with the SMAQ, DMS, and MBIDS, and each scale was considered clear, adequate, and understandable. Through this process, final versions of each scale were prepared in Portuguese for use in the present study.

\section{Procedures}

Ethical approval for this study was obtained from the relevant university ethics committee. The recruitment of participants was nonprobabilistic and the researches visited universities, army quarters, and a multinational industrial organization to orally invite potential participants to voluntarily take part in the study. Researchers informed the participants that the study was focused on men's health, explaining that their data would help to validate instruments to evaluate aspects of body image among men. The survey, in which the above scales were counterbalanced for each participant, was completed in a quiet location. A consent form explained the procedures and objectives of the study, and it was read and signed by all participants. Each respondent took approximately 20 minutes to complete the survey. All participants took part on a voluntary basis and were not remunerated for participation.

\section{Scale Models}

All three scales included in this study have already had their factorial structure determined with exploratory factor analysis in their initial or posterior validity studies (Edwards \& Launder, 2000; Kimmel \& Mahalick, 2004; McCreary et al., 2004) and a good deal of research about drive for muscularity has developed in the last decade (McCreary, 2011). Based on these advances, which provides evidence about the psychometric properties of the included scales, associated factors, and predictors of drive for muscularity, we felt that at this point the best approach for the present study would be to test the factorial models as predicted by existing theory using confirmatory factor analysis (CFA).

Confirmatory factor analysis enabled us to evaluate how well the observed variables (item of the scales) represent the construct. CFA requires a factorial model, hypothesized a priori based on theory, to assess how well the theoretical specification matches the observed data, confirming or rejecting the preconceived theory (Hair, Anderson, Tatham, \& Black, 2009). It is a robust approach and has also been recommended for cross-cultural research (Watkins, 1989), given the fact that CFA provides a better way of comparing factor structures and test competing models, which is of especial importance in determining cross-cultural differences or similarities.

Regarding the DMS, prior evidence confirmed the pertinence of muscularity concern and the desire of being more muscular to the drive for muscularity attitude component and a behavioral component focused on achieving a more muscular body (Cafri \& Thompson, 2004; Litt \& Dodge, 2008; McCreary et al., 2004; McPherson et al., 2010; Wojtowicz \& von Ranson, 2006). In short, the two factor model of the DMS seems to explain well the drive for muscularity aspects assessed by the scale.

However, this two-factor theoretical model excludes an important attitudinal aspect of drive for muscularity, namely the ambiguity of the investment in muscularity. It exists because of the nonlegitimation of the concern with appearance, sometimes considered a feminine aspect. In this way, criticism of the amount of physical training, of supplementary resources use for muscle gain, and of time spent on appearance care are not unusual among young men (Adams, Turner, \& Bucks, 2005; Davis, Karvinen, \& McCreary, 2005; Grogan \& Richards, 2002; McCreary, 2007; Pope, Phillips, \& Olivardia, 2000). The DMS includes items that, conceptually at least, may assess these feelings of ambiguity. Because of this distinct attitudinal aspect and based on the available literature and on item content analysis, we proposed a new theoretical model for the DMS, with three factors: (1) muscularity concern (items 1, 7, 9, 11, 13, 14, and 15); (2) muscularity investment (items 2, 3, 4, and 5); and (3) ambiguity of muscularity investment (items $6,8,10$, and 12). We also investigated the original twofactor solution of the DMS (McCreary et al., 2004) with one difference: we considered item 10 in factor 2, based on the advice of recent transcultural scholars (McPherson et al., 2010).

In the case of the SMAQ, the available literature points to an association between muscularity and masculinity (Adams et al., 2005; Grogan \& Richards, 2002; McCreary, Saucier, \& Courtenay, 2005; Morrison, Morrison, \& Hopkins, 2003).

Particularly in Brazil, masculinity is recognized as a social benefit focused on muscularity, as separate from confidence and physical attractiveness (Fontes, 2009; Sabino, 2000). Because of this cultural aspect, we proposed a three-factor model for the Brazilian version of SMAQ. Factor 1, muscularity investment, is concerned with the desire and predisposition to invest in a muscular body. Factor 2, muscularity general benefits, is concerned with varied benefits, such as physical attractiveness, confidence, 
and well-being. Finally, Factor 3, muscularity and masculinity, is concerned with the rise in masculinity associated with increased muscularity. Elsewhere (Morrison \& Morrison, 2006), a threefactors solution for the SMAQ has been proposed using confirmatory factor analysis. However, because this three-factor solution violates the recommendation of having, at least, three items per factor (Pedhazur, 1997), we decided not carry examine this factor structure. In short, we only examined the original two-factor solution (Edwards \& Launder, 2000), as well as our new proposed theoretical model (see Figure 1).

The masculine body ideal is basically centered on the welldefined and muscular body, being the concerns regarding muscularity that are more salient than those regarding to adiposity (McCreary, 2011). Each item of the MBIDS illustrates a component of this masculine body ideal (Bottamini \& Ste-Marie, 2006; Calden, Lundy, \& Schalafer, 1959; Kimmel \& Mahalick, 2004; Lilleaas, 2007; Ridgeway \& Tylka, 2005; Tager, Good, \& Morrison, 2006) and we found no evidence to support any other model than the original unidimensional model. In view of this, for the MBIDS, we only investigated the pertinence of the theory under original model for Brazilian data.

\section{Statistical Analysis}

In order to prepare the data for CFA analysis in the PRELIS2 version of the LISREL system, the listwise deletion criterion was adopted for missing data--resulting in the elimination of cases with missing answers (Jöreskog \& Sörbom, 1999). After generating the PRELIS file, the SIMPLIS model was used, which is an encoding of the LISREL system. CFA was then conducted, making it possible to evaluate the parameters of the construct of the measuring model. Given the fact that our data were not normally distributed, to estimate the models, the unweighted least square method was used because it is not sensitive to lack of multivariate normality (Garson, 2006). The CFA was computed using LISREL 8.51 .

Because the value of the standardized chi-square is inflated with large samples and values less than 5.0 do not characterize the adjustments (Maruyama, 1998), we considered the following fit indices for the adjustment of models: goodness-of-fit index (GFI), adjusted goodness-of-fit index (AGFI), normed fit index (NFI), non-normed fit index (NNFI), and comparative fit index (CFI). According to the literature (Hair et al., 2009), these indices should be equal to or above .90 . Also considered was the root mean square error of approximation (RMSEA), whose established value of acceptance is below .08. In order to compare models, three parsimony fit indices were considered: Akaike's information criterion (AIC), parsimony normed fit index (PNFI), and parsimony goodnessof-fit index (PGFI). There are no reference values for those indices, but smaller AIC and greater PNFI and PGFI are preferable (Hair et al., 2009). For models with initial poor adjustment, factorial loadings, items residuals, and LISREL modification indices were considered for further adjustments.

To analyze the measurement model, construct validity (discriminant and convergent) and internal consistency were examined. To establish the latter, Cronbach's alphas and construct reliability were measured (Hair et al., 2009). Construct reliability is given by the formula: (squared sum of the standardized factor load)/ (squared sum of the standardized factor load + the sum of the measurement error of the indicator). Values greater than or equal to 0.70 are acceptable.

To establish the convergent validity, $t$-values and the factorial loads of the observable variables were analyzed. Item factorial loads greater than 0.50 were preferable; however,

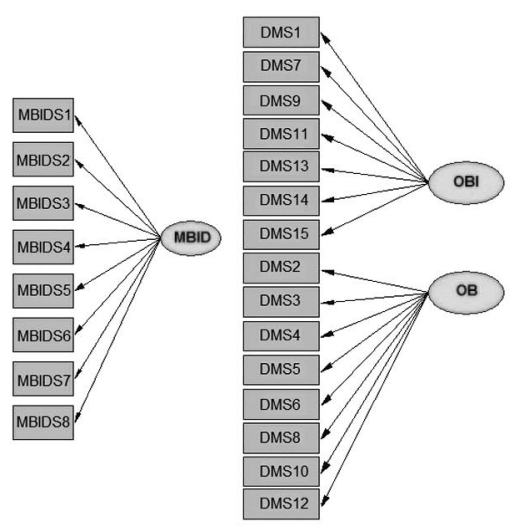

A

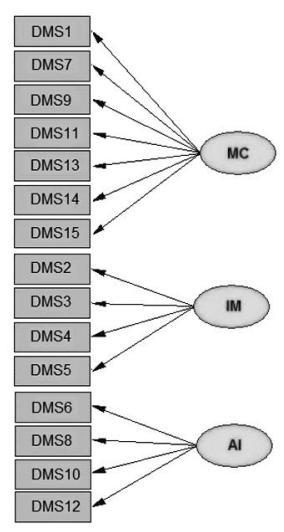

C

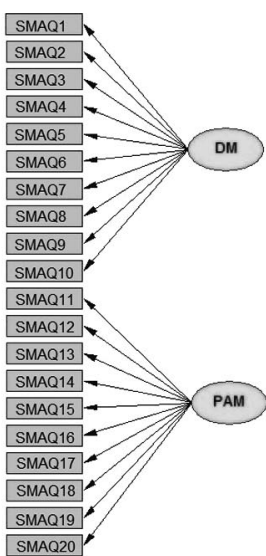

D

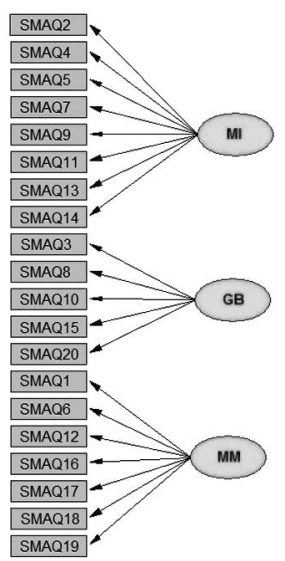

$\mathrm{E}$

Figure 1. Models for MBIDS, DMS and SMAQ. (A) = original model of MBIDS; (B) $=$ original model of DMS; $(C)=$ new theoretical mode for DMS; (D) = original model of SMAQ; (E) = new theoretical model for SMAQ. Circles are latent variables (factors) and rectangles are observed variables (items). OBI = muscularity oriented body image; $\mathrm{OB}=$ muscularity oriented behavior; $\mathrm{MC}=$ muscularity concern; $\mathrm{IM}=$ muscularity investment; $\mathrm{AI}=$ ambiguity of muscularity investment; $\mathrm{DM}=$ drive for muscularity; $\mathrm{PAM}=$ positive attributes of muscularity; $\mathrm{MI}=$ muscularity investment; $\mathrm{GB}=$ muscularity general benefit; $\mathrm{MM}=$ muscularity and masculinity. 
Table 1

Comparison Between the DMS Models

\begin{tabular}{ccccccccccccc}
\multicolumn{1}{c}{ Models } & $\chi^{2} / d f$ & RMSEA & NFI & NNFI & CFI & GFI & AGFI & AIC & PNFI & PGFI & $(+) \mathrm{R}$ & $(-) \mathrm{R}$ \\
\hline Original model & 4,98 & .067 & .99 & .99 & .99 & .99 & .99 & 299,28 & 0,72 & 0,61 & 3,43 & $-3,06$ \\
Theoretical model & 4,97 & .067 & .99 & .99 & .99 & .99 & .99 & 351,21 & 0,72 & 0,62 & 3,48 & $-3,10$ \\
\hline
\end{tabular}

Note. $\quad$ RMSEA $=$ root mean square error of approximation; NFI $=$ normed fit index; NNFI $=$ nonnormed fit index; CFI = comparative fit index; GFI $=$ goodness-of-fit; AGFI $=$ adjusted goodness-of-fit; $\chi^{2} / d f=$ $\chi$-weighted square; AIC = Akaike information criterion (model); PNFI = parsimony normed fit index; PGFI = parsimony goodness-of-fit index; (+)higher positive residual; (-) higher negative residual. References values: Chi-weighted square $=$ below 5 ; RMSEA $=$ below .08 ; NFI, NNFI, CFI, GFI, and AGFI $=$ above .90

because of our sample size, values of .30 were deemed acceptable (Hair et al., 2009). In the present case, $t$-values greater than or equal to 1.96 were considered acceptable (Garver \& Mentzer, 1999). To evaluate discriminant validity, Fornell and Lacker (1981) suggest a comparison between the average variance extracted (AVE) for each factor and the shared variance (squared correlations) of each pair of factors. The AVE is given by the formula: (sum of the squared standardized factor load)/ (sum of the squared standardized factor load + the sum of the measurement error of the indicator). The AVE should be greater than .50 and greater than the value of all shared variance. For MBIDS, discriminant validity was evaluated by checking the negative association of its score with BAS score, given the fact that a comparison between AVE and shared variance could not be done in a unidimensional scale.

\section{Results}

\section{DMS Factor Structure}

First, we tested the two-factor model proposed by McCreary et al. (2004), modified so that item 10 was added to the second factor (McPherson et al., 2010). Initial results showed poor adjustments $\left(\chi^{2}=1603.51, p<.001\right.$; RMSEA $=.139$, GFI $=$ .972 , AGFI $=.962$, NFI $=.958$, CFI $=.964$, NNFI $=.958$, $\left.\chi^{2} / d f=18.01\right)$. The composition that showed best adherence $\left(\chi^{2}=239.28, p<.001 ;\right.$ RMSEA $=.067, \mathrm{GFI}=.992, \mathrm{AGFI}=$ $\left..986, \mathrm{NFI}=.987, \mathrm{CFI}=.992, \mathrm{NNFI}=.989, \chi^{2} / \mathrm{gl}=4.98\right)$ was the one where items 7,9 , and 10 were eliminated, because of their high residuals (see Figure 2).

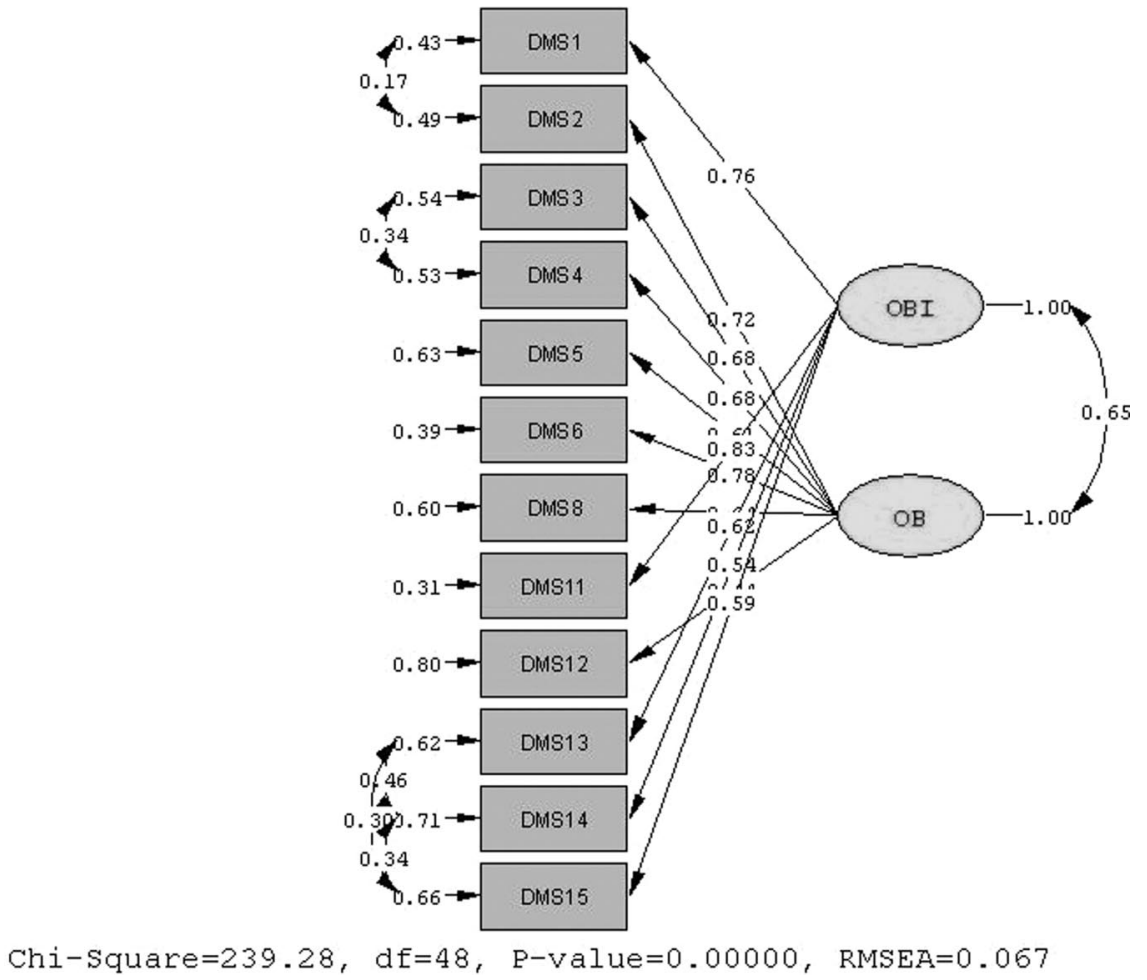

Figure 2. Fitted model for Brazilian translation of DMS; OB $=$ muscularity oriented-behavior factor. OBI $=$ oriented body image factor. 
Second, we tested the new theoretical model with three factors. The first adjustment of this model was likewise poor $\left(\chi^{2}=\right.$ $1399.38, p<.001 ;$ RMSEA $=.131, \mathrm{GFI}=.974$, AGFI $=.965$, $\left.\mathrm{NFI}=.962, \mathrm{CFI}=.968, \mathrm{NNFI}=.962, \chi^{2} / d f=16.08\right)$. On the best composition for this model $\left(\chi^{2}=283.21, p<.001\right.$; RMSEA $=.067$, GFI $=.992$, AGFI $=.987$, NFI $=.987$, CFI $=$ .992 , NNFI $\left.=.990, \chi^{2} / d f=4.97\right)$, items 10 and 7 were eliminated because of associated residuals.

The two adjusted models were compared to determine the best models for the Brazilian Portuguese version of the DMS (see Table 1 for model comparisons). The model proposed by McCreary et al. (2004) was chosen for the Brazilian DMS. Both models have near identical RMSEA, CFI, NFI, NNFI, AGFI, and GFI indices, but the model proposed by McCreary et al. (2004) model has a lower AIC value (299.28; AIC rival model $=351.21$ ) and lower values for residuals (higher positive residual $=3.43$; higher negative residual $=$ -3.06) when compared to the rival theoretical model (higher positive residual $=3.84$; higher negative residual $=-3.10$ ). These parameters indicate that McCreary et al.'s (2004) model has greater parsimony and better explains the observed data.

\section{Internal Consistency, and Discriminant and Convergent Validity of DMS}

For the chosen model, the factors muscle-oriented body image and muscle-oriented behavior, had good values for internal consistency, with $\alpha=.87$ and construct reliability of 0.80 , and $\alpha=$ .86 and construct reliability of 0.81 , respectively.

The two factors correlated at $r=.65, p<.001$. Factor 1's AVE was .46 and Factor 2's AVE was .43. AVEs of the two factors were higher than the shared variance of the factors, .42 .

All items' $t$-values were above 1.96. All factor loadings were adequate, with items $12\left(\lambda_{\mathrm{i}}=.44\right), 14\left(\lambda_{\mathrm{i}}=.54\right)$, and $15\left(\lambda_{\mathrm{i}}=.59\right)$ having the lowest loadings. These parameters give evidences of convergent validity (Garver \& Mentzer, 1999; Hair et al., 2009). Additionally, correlations between duration, frequency, and intensity of exercise practice, general body appreciation and the DMS factors were investigated (see Table 4). Greater physical exercise frequency, intensity, and duration were significantly correlated with higher scores of the muscularity-oriented body image factor of the DMS ( $r \mathrm{~s}=.29-.39$ ). We also found positive correlations between intensity, frequency, duration of physical exercise and muscularity-oriented behavior factor ( $r \mathrm{~s}=.09-.10)$, although the strength of these correlations were weaker than those for the former factor. The latter DMS factor was also significantly and negatively correlated with general body appreciation $(r=-.31)$.
A Mann-Whithey test indicated that there were no significant differences between single and romantically involved men on the muscularity-oriented body image factor scores, $U=71723, p=$ $.670, r=.015$, or the muscularity-oriented behavior factor, $U=$ 71723, $p=.810, r=.008$ ).

\section{SMAQ Factor Structure}

Initially, we tested the model proposed by Edwards and Launder (2000). Initial adjustments were poor $\left(\chi^{2}=3226.79, p<.001\right.$; RMSEA $=.145$, GFI $=.943$, AGFI $=.929$, NFI $=.921$, CFI $=$ .928, NNFI $\left.=.919, \chi^{2} / d f=19.33\right)$. Following the chosen parameter to proceed with modifications on the model, items $3,9,14$, and 20 were eliminated for their low factorial loadings, and items 7, 12, 15, 16, and 19 for their high residuals. Following these changes, better adjustment of this model was achieved $\left(\chi^{2}=\right.$ $148.35, p<.001 ;$ RMSEA $=.056$, GFI $=.992$, AGFI $=.995$, $\left.\mathrm{NFI}=.992, \mathrm{CFI}=.997, \mathrm{NNFI}=.995, \chi^{2} / d f=3.71\right)$, although only 11 items from the original scale remained in this model.

A proposed three-factor theoretical model for the SMAQ also had poor initial adjustments $\left(\chi^{2}=1520.25, p<.001\right.$; RMSEA $=.096$, $\mathrm{GFI}=.972, \mathrm{AGFI}=.965, \mathrm{NFI}=.961, \mathrm{CFI}=.968, \mathrm{NNFI}=$ $\left..964, \chi^{2} / g l=9.10\right)$. To achieve better adjustment, first item 19 was eliminated (residuals), followed by items 9 (low factorial loading and residuals), 7 (residuals), 14 (low factorial loading and residuals), and 15 (residual). The new estimation presented adjustment measures above acceptance levels $\left(\chi^{2}=266.62, p<.001\right.$; RMSEA $=.050$, GFI $=.993$, AGFI $=.990, \mathrm{NFI}=.990, \mathrm{CFI}=$ $\left..996, \mathrm{NNFI}=.995, \chi^{2} / d f=3.17\right)$.

Despite the lower AIC index of Edwards and Launder's (2000) model (AIC $=200.35)$, when compared with the new theoretical model (AIC $=338.82$ ), the latter showed better adjustment on three other parsimony indices (PGFI, PNFI, and $\chi^{2} / d f$ ), as well as better RMSEA adjustment and lower residuals, showing that the model better explains the observed data. For these reasons, the decision was made to adopt the new theoretical model for the Brazilian SMAQ (see Table 2 for model comparisons and Figures 3 and 4 for the fitted chosen model).

\section{Internal Consistency and Discriminant and Convergent Validity of the SMAQ}

Cronbach's alpha coefficients indicate a high level of internal consistency for Factor $1(\alpha=.90)$, Factor $2(\alpha=.83)$, but not for Factor $3(\alpha=.64)$. However, the construct reliability coefficients indicate a satisfactory level of internal reliability for Factor 3

Table 2

Comparison Between the SMAQ Models

\begin{tabular}{lccccccccccccc}
\hline \multicolumn{1}{c}{ Models } & $\chi^{2} / d f$ & RMSEA & NFI & NNFI & CFI & GFI & AGFI & AIC & PNFI & PGFI & $(+)$ R & $(-) \mathrm{R}$ \\
\hline Original model & 3,71 & .056 & .99 & .99 & 1 & .99 & .99 & 200,35 & 0,72 & 0,60 & 3,40 & $-2,59$ \\
Theoretical model & 3,17 & .050 & .99 & .99 & 1 & .99 & .99 & 338,62 & 0,79 & 0,69 & 2,62 & $-2,64$ \\
\hline
\end{tabular}

Note. $\quad$ RMSEA $=$ root mean square error of approximation; $\mathrm{NFI}=$ normed fit index; $\mathrm{NNFI}=$ nonnormed fit index; CFI = comparative fit index; GFI $=$ goodness-of-fit; AGFI $=$ adjusted goodness-of-fit; $\chi^{2} / d f=$ $\chi$-weighted square; AIC $=$ Akaike information criterion $($ model $) ;$ PNFI $=$ parsimony normed fit index; PGFI = parsimony goodness-of-fit index; $(+)$ higher positive residual; $(-)$ higher negative residual. References values: Chi-weighted square = below 5 ; RMSEA = below .08; NFI, NNFI, CFI, GFI, and AGFI = above .90 


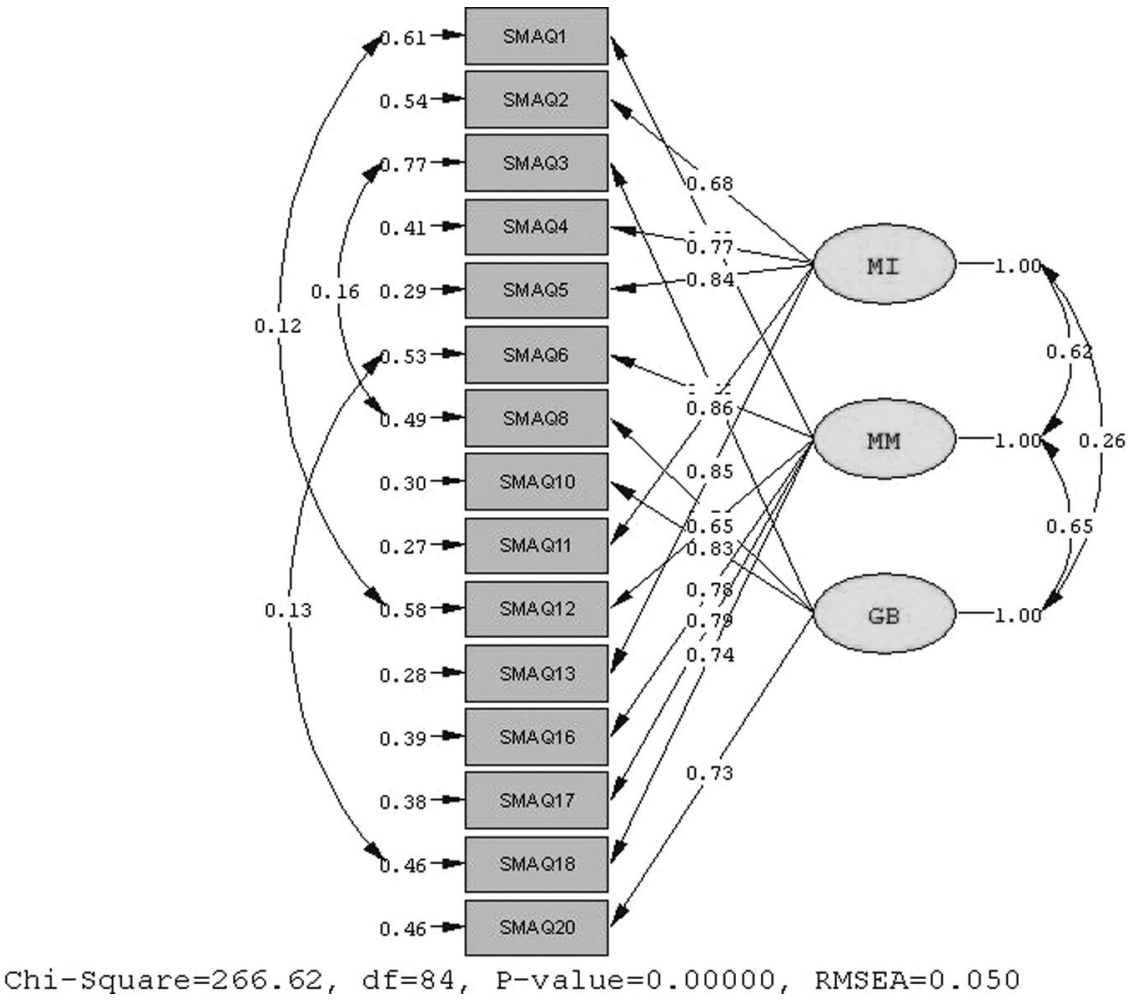

Figure 3. Fitted model for Brazilian translation of SMAQ. IM = investment in muscularity factor; MM = masculinity and muscularity factor; $\mathrm{GB}=$ muscularity general benefit factor.

$(\mathrm{CR}=.79)$. The test also confirmed the high levels of internal reliability for Factors $1(\mathrm{CR}=.90)$ and $2(\mathrm{CR}=.83)$.

All $t$-values were above 1.96 and all factorial loading were above .50 , giving evidence of the convergent validity of the model (Garver \& Mentzer, 1999). Discriminant validity was checked through the AVE analysis (Fornell \& Larcker, 1981). As we can see in Table 3, results provided evidence of discriminant validity for the three factors, fulfilling all the conditions: all AVEs were above .50 and all AVEs were superior to the shared variance of each pair of factors. As a further investigation of convergent validity, correlations between frequency, intensity and length of physical exercise practice, general body appreciation and SMAQ scores were analyzed (see Table 4). Scores of muscularity investment factor were weakly correlated with physical exercise intensity, frequency, and duration, and general body appreciation ( $r \mathrm{~s}=$ .09 to -.17$)$. The muscularity and masculinity factor had no significant associations with the frequency of physical exercise and showed significant but weak correlations with physical exercise intensity, and duration, and general body appreciation $(r \mathrm{~s}=$ .09 to -.15 ). The muscularity general benefit factor had significant correlations with all remaining variables $(r s=.14$ to -.27$)$.

As an aside, we also looked for differences on SMAQ factors as a function of marital status. No score differences were found between single and committed men on the Investment factor, $U=$ $67791, p=.420, r=.029$, the muscularity and masculinity factor, $U=71985, p=.910, r=.004$, or the muscularity general benefit factor, $U=68999, p=.30, r=.037$.

\section{MBIDS Factor Structure}

As with the DMS and SMAQ, initial parameters showed the need for further adjustments on the MBIDS $\left(\chi^{2}=336.04, p<.001\right.$; RMSEA $=.134$, GFI $=.988$, AGFI $=.979$, NFI $=.981$, CFI $=$ .984, NNFI $\left.=.978, \chi^{2} / d f=16.8\right)$. The LISREL modification indices, factor loadings, and model residuals were analyzed and better adjustment was achieved after we allowed for error covariance between items 8 and 5, and following the exclusion of items 1 and 6 because of their high residuals $\left(\chi^{2}=27.51, p<.001\right.$; RMSEA $=.053$, GFI $=.998$, AGFI $=.995$, NFI $=.996$, CFI $=$ .999 , NNFI $=.999, \chi^{2} / d f=3.43$; see Figure 4 for the fitted model).

\section{Internal Consistency and Discriminant and Convergent Validity of the MBIDS}

Cronbach's alpha for the MBIDS value was .84 and the value of construct reliability was .82 . Both tests gave evidence of scale internal consistency. In respect of convergent validity, all factors loadings were above .05 and all $t$-values had statistical significance, being above of 1.96. Also, following Kimmel and Mahalik's (2004) recommendation to explore the association among their new scale and other muscularity measures, we did so using bivariate correlations. As expected, the correlations among the factors of the three scales were significant. Weak, but significant correlations among MBIDS and physical exercise parameter of practice (frequency, intensity, and duration) were also found (see 


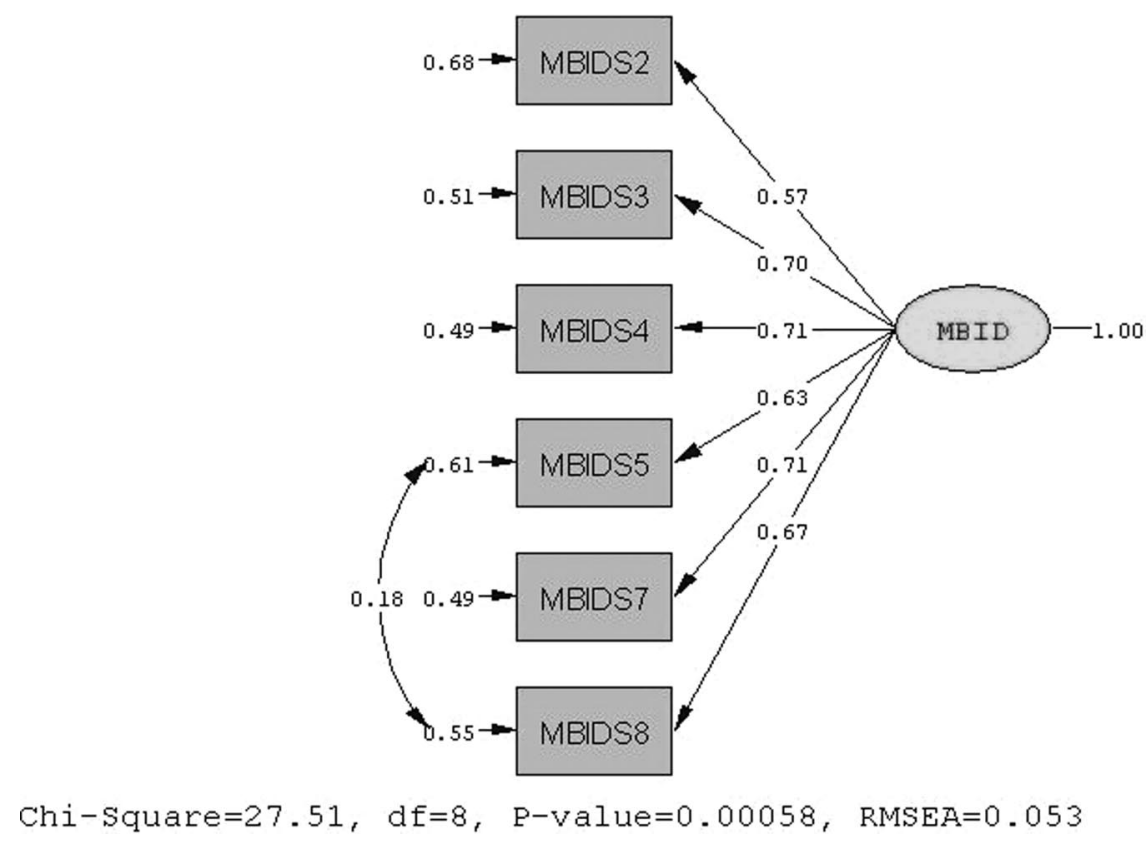

Figure 4. Fitted model for Brazilian translation of MBIDS. MDID = Masculine Body Ideal Distress factor.

Table 4). Discriminant validity of the MBIDS was checked by correlations between BAS and MBIDS scores. As expected, the two scales had a significant and negative correlation $(r=-.16)$. Finally, for the MBIDS, a Mann-Whitney test showed no score differences between committed and single men, $U=72763, p=$ $.610, r=.018$.

\section{Discussion}

The main aim of the present study was to translate into Brazilian Portuguese and establish the factorial structure and psychometric properties of the DMS, SMAQ, and MBIDS. In the first instance, we found that the original two-factor structure of DMS (McCreary et al., 2004) had the best fit for our Brazilian data. Despite the two tested models achieving good fit indices, the original structure was considered the best solution, especially because of its lower residuals and parsimony, which indicate that this model better explains the observed data. In addition, DMS factor scores derived from the two-factor model showed adequate values of internal consistency and satisfactory evidence of convergent and discriminant validity.

Table 3

Average Variance Extracted and Shared Variance on Brazilian SMAQ

\begin{tabular}{llll}
\hline \multicolumn{1}{c}{ Factors } & 1 & 2 & 3 \\
\hline 1. Muscularity Investment (MI) & $\mathbf{. 6 4}$ & .62 & .25 \\
2. General Benefits (GB) & .38 & $\mathbf{. 5 1}$ & .64 \\
3. Masculinity and Muscularity (MM) & .06 & .41 & $\mathbf{. 5 0}$ \\
\hline
\end{tabular}

Note. The values of average variance extract are in the diagonal line, on bold. Below the diagonal, are the values of the shared variance of each pair of factors. Above the diagonal, are the correlations between each factor.
It is also worth considering the correlations found among practices of physical exercise and DMS factors. We found that there were significant correlations between muscle-oriented body image and exercise habits, which provide support for the convergent validity of the Brazilian Portuguese DMS. On the other hand, although the correlations between exercise habits and the muscularity-oriented behaviors subscale were weaker, it should be noted that this is consistent with previous work (Chittester \& Hausenblas, 2009; Kelley, Neufeld, \& Musher-Eizenmam, 2010; Pickett \& Cash, 2005). Economic factors (e.g., the need to pay to use a gym), social factors (e.g., leisure time to go to the gym), and emotional factors (e.g., anxiety, appearance concern) are known barriers to the behavioral expression of drive for muscularity. In Brazil, specifically, it is possible that economic factors play an important role in shaping physical activity habits (Matsudo, 2002) and, from this perspective, the weaker associations between DMS muscularity-oriented behavior and exercise habits is to be expected.

We also confirmed the original structure for a second translated scale, the MBIDS. As this scale focuses primarily on the muscular components for an ideal body, a unidimensional solution seems adequate a priori and was also supported in the present study. Indeed, the model of the Brazilian version of the MBIDS had good adjustment, high internal consistency values, and evidence of good convergent and discriminant validity. In terms of the latter, we were able to confirm the prediction that MBIDS would be negatively associated with general body appreciation. It is our recommendation that the Brazilian version of the MBIDS be used concomitantly with other measures, especially those related with appearance investment and drive for muscularity, as the communion of these measures could provide a better understanding of corporeal behaviors associated with muscle development. 
Table 4

Spearman's Correlations Among MBIDS and DMS Factors, MBIDS, BAS, and Physical Exercise Parameters of Practice

\begin{tabular}{lrllllllllll}
\hline & $M$ & $S D$ & 1 & 2 & 3 & 4 & 5 & 6 & 7 & 8 & 9 \\
\hline 1. MBID & 16.90 & 4.51 & & & & & & & & \\
2. DMS-OB & 15.74 & 7.5 & $.39^{* * *}$ & & & & & & & \\
3. DMS-OBI & 14.96 & 5.95 & $.36^{* *}$ & $.50^{* * *}$ & & & & & & \\
4. SMAQ-IM & 5.88 & 4.59 & $.29^{* * *}$ & $.46^{* *}$ & $.59^{* *}$ & & & & & \\
5. SMAQ-MM & .42 & 1.18 & $.14^{* * *}$ & $.22^{* * *}$ & $.24^{* *}$ & $.27^{* *}$ & & & & \\
6. SMAQ-GB & 2.88 & 3.58 & $.36^{* * *}$ & $.46^{* * *}$ & $.50^{* * *}$ & $.56^{* *}$ & $.38^{* *}$ & & & \\
7. BAS & 40.91 & 6.15 & $-.16^{* *}$ & $\mathrm{n} / \mathrm{s}$ & $-.31^{* *}$ & $-.17^{* *}$ & $-.15^{* *}$ & $-.27^{* * *}$ & & \\
8. PE_I & 2.67 & 1.77 & $.17^{* *}$ & $.34^{* * *}$ & $.10^{* *}$ & $.11^{* *}$ & $.09^{* *}$ & $.20^{* * *}$ & $.08^{*}$ & & \\
9. PE_F & 2.98 & 1.61 & $.13^{* * *}$ & $.29^{* * *}$ & $.10^{* *}$ & $.09^{* *}$ & $\mathrm{n} / \mathrm{s}$ & $.14^{* * *}$ & $\mathrm{n} / \mathrm{s}$ & $.67^{* *}$ & \\
10. PE_D & 3.08 & 1.71 & $.16^{* *}$ & $.39^{* * *}$ & $.09^{* *}$ & $.12^{*}$ & $.12^{* *}$ & $.19^{* *}$ & $.10^{* * *}$ & $.63^{* *}$ & $.71^{* *}$ \\
\hline
\end{tabular}

Note. $\quad M=$ mean; $S D=$ standard deviation; MBIDS = Masculine Body Ideal Distress Scale; DMS-OB = muscularity oriented-behavior factor, Drive for Muscularity Scale; DMS-OBI = oriented body image factor, Drive for Muscularity Scale; SMAQ-IM = investment in muscularity factor, Swansea Muscularity Attitudes Questionnaire; SMAQ-MM = masculinity and muscularity factor, Swansea Muscularity Attitudes Questionnaire; SMAQ-GB = muscularity general benefit factor, Swansea Muscularity Attitudes Questionnaire; BAS = general body appreciation factor from Body Appreciation scale; PE-I = physical exercise intensity; PE_F = physical exercise frequency; PE-D = physical exercise duration.

${ }^{*}$ Correlation significant at .05 level. ${ }^{* * *}$ Correlation significant at .01 level.

The results of this study also suggest that an alternative solution for the SMAQ is more suitable for our data. In fact, both the original and the new models achieved similar fit adjustments. However, the new model had better adjustment in three of the four parsimonious measures of comparison for non-nested models (Hair et al., 2009), a better absolute adjustment, and lower residuals. In short, the fit indices suggested that the new model better explains the observed data and, in addition, also showed satisfactory evidence of internal consistency and convergent and discriminant validity. The proposed model for the SMAQ, with a threefactor solution, distinguishes between investment in muscularity attitudes, benefits of a muscular body, and the association of muscularity and masculinity. The advantage of this model, in relation of the original two-factor solution model (Edwards \& Launder, 2000) is the possibility to evaluate, with a specific muscularity measure, the associations between muscularity and masculinity, which may be particularly important in contexts marked by changing gender roles and equality (Swami \& Voracek, in press). This kind of research has already been conducted using qualitative approaches (Adams et al., 2005; Grogan \& Richards, 2002; Morrison et al., 2003), but is less explored in large samples (McCreary et al., 2005). Our results suggest that this association may benefit from more in-depth focus in future research. Moreover, we also found significant associations between the three scales, MBIDS and the factors derived from the DMS and SMAQ, which provides further evidence of the convergent validity of each of these scales.

We were also able to analyze the factors scores for variation as a function of marital status. For this Brazilian sample, our results suggested that there were no significant differences between single and committed men on DMS, SMAQ, and MBIDS factors scores. Previous research has indicated that the muscular body ideal is more prominent among single compared with dating men (Giles \& Close, 2008). In addition, romantic partner opinions have an influence on body investment for men (Luciano, 2001). By contrast, the lack of significant differences in our sample appears to indicate that relationship status does not impact attitudes toward muscularity, perhaps because the muscular ideal is so ubiquitous within the Brazilian context (Goldenberg, 2002). Of course, further research about this topic is necessary, and such research could explore the quality and the length of the relationship or sexual activity for a better understanding of the differences and similarities between single and committed men.

We should like to comment on our analytic decision, made for all three scales, to accept the covariance errors between items, as suggested by the LISREL's modification indices. Common causes for this include item redundancy (caused by similar content or social desirability) and/or an omission of an exogenous factor (Schumacker \& Lomax, 2004). The acceptance of covariance error should have theoretical support, rather than a purely statistical reason (e.g., to enhance the model adjustment; Silvia \& Maccallum, 1988). It is unlikely that social desirability is a factor for error covariance, since we ensured conditions for data collection to reduce this bias (voluntary and anonymous participation). It is also unlikely that an ignored latent variable (factor) was missing in the three scales, since the analyzed models were, in one hand, already proposed and investigated by previously studies and, on the other hand, based on qualitative and qualitative body image and drive for muscularity research. It is, therefore, possible that the existence of error covariance was due to similar content between items (Hatoum \& Belle, 2004), which will require further consideration, particularly in terms of the DMS and MBIDS.

Finally, it is also worth considering that all three translated scales lost one or more items: the DMS lost items 7, 9, and 10; the SMAQ lost items 7, 9, 14, 15, and 19, and; the MBIDS lost two items. Again, it is unlikely that a translational issue caused this problem, as we took careful steps to ensure that the scales in the present study were translated reliably. It is more plausible that cultural differences led to this situation: specifically, it is possible that there are some aspects of men's corporeal experiences that are specific to Brazil and that may impact upon drive for muscularity. From this perspective, the eliminated items could be considered to 
be less relevant to the concept of drive for muscularity and body ideals among Brazilian men. Indeed, previous studies have suggested discrepancies between scales developed in the West and translated into Brazilian Portuguese (Campana, Tavares, Silva, \& Diogo, 2009; Gouveia, Singelis, \& Coelho, 2002; Swami et al., 2011).

A number of further limitations of the present study should be considered. First, we have only validated these scales for a specific group of young Brazilian men. Since drive for muscularity is considered to be an important part of men's body image (McCreary, 2011), it would be interesting to have drive for muscularity measures for Brazilian adolescents and older adults as well. In a similar vein, the opportunistic method of recruiting participants means that the present results should only be generalized to the wider population with caution. Future studies should also examine the psychometric properties of the Brazilian DSM, SMAQ, and MBIDS among specific samples in which muscularity has a prominent importance, both for its function (e.g., athletes in general) and its appearance (e.g., bodybuilders). Because this paper focused on men, and because drive for muscularity is also present in women, a similar psychometric study for Brazilian women is also needed. In fact, we still need to investigate the extent of relations and associations that drive for muscularity could have with other relevant constructs, such as exercise dependence, anabolic steroid use, social physique anxiety, and physical attraction, in the Brazilian context. Similarly, it would also be useful to examine associations between these scales and wider range of demographic factors; for example, socioeconomic status may be an important neglected factor in the present study, given associations between body image measures and socioeconomic status reported in other developing contexts (e.g., Swami, Kannan, \& Furnham, in press).

In conclusion, the present study provides evidence for the psychometric properties of Brazilian Portuguese versions of the DMS, SMAQ, and MBIDS. Consider the relatively poor state of quantitative research on men's body image in the Brazilian context (Campana \& Tavares, 2009), we hope that the availability of these scales will allow for more systematic investigations of men's drive for muscularity in Brazil. More broadly, the availability of these scales raises the possibility of conducting systematic cross-cultural research that includes a nation known for its "cult of the body."

\section{References}

Adams, G., Turner, H., \& Bucks, R. (2005). The experience of body dissatisfaction in men. Body Image, 2, 271-283. doi:10.1016/j.bodyim .2005 .05 .004

Avalos, L., Tylka, T. L., \& Wood-Barcalow, N. (2005). The Body Appreciation Scale: Development and psychometric evaluation. Body Image, 2, 285-297. doi:10.1016/j.bodyim.2005.06.002

Beaton, D. E., Bombardier, C., Guillemin, F., \& Ferraz, M. B. (2002). Recommendations for the cross-cultural adaptation of healthy status measures. Chicago, IL: American Academy of Orthopedic Surgeons/ Institute for Work \& Health.

Bergeron, D. P., \& Tylka, T. L. (2007). Support for the uniqueness of body dissatisfaction from Drive for Muscularity among men. Body Image, 4, 288-295. doi:10.1016/j.bodyim.2007.05.002

Bottamini, G., \& Ste-Marie, D. M. (2006). Male voices on Body image. International Journal of Men's Health, 5, 109-132. doi:10.3149/jmh .0502 .109

Cafri, G., Strauss, J., \& Thompson, J. K. (2002). Male body image: Satisfaction and its relationship to well-being using the Somatomorphic
Matrix. International Journal of Men's Health, 1, 215-231. doi:10.3149/ jmh.0102.215

Cafri, G., \& Thompson, J. K. (2004). Measuring male body image: A review of current methodology. Psychology of Men \& Masculinity, 5, 18-29. doi:10.1037/1524-9220.5.1.18

Cafri, G., \& Thompson, J. K. (2007). Measurement of the muscular ideal. In J. K. Thompson \& G. Cafri (Eds.), The muscular ideal: Psychological, social, and medical perspectives (pp. 107-120). Washington, DC: American Psychological Association. doi:10.1037/11581-005

Calden, G., Lundy, R. M., \& Schlafer, R. J. (1959). Sex differences in Body Concepts. Journal of Consulting Psychology, 23, 378. doi: $10.1037 / \mathrm{h} 0046643$

Campana, A. N. N. B., Tavares, M. C. G. C. F., Silva, D., \& Diogo, M. J. D. (2009). Translation and validation of Body Image Avoidance Questionnaire (BIAQ) to the Portuguese Language in Brazil. Behavior Research Methods, 41, 236-243. doi:10.3758/BRM.41.1.236

Campana, A. N. N. B., \& Tavares, M. C. G. C. F. (2009). Body image assessment measures and guidelines for research. São Paulo, Brazil: Phorte.

Chittester, N. I., \& Hausenblas, H. A. (2009). Correlates of drive for muscularity: The role of anthropometric measures and psychological factors. Journal of Health Psychology, 14, 872-877. doi:10.1177/ 1359105309340986

Davis, C., Karvinen, K., \& McCreary, D. R. (2005). Personality correlates of a Drive for Muscularity in young men. Personality and Individual Differences, 39, 349-359. doi:10.1016/j.paid.2005.01.013

Dorneles de Andrade, D. (2010). On norms and bodies: Findings from field research on cosmetic surgery in Rio de Janeiro, Brazil. Reproductive Health Matters, 18, 74-83. doi:10.1016/S0968-8080(10)35519-4

Edmonds, A. (2007). "The poor have the right to be beautiful": Cosmetic surgery in neoliberal Brazil. Journal of the Royal Anthropological Institute, 13, 363-381. doi:10.1111/j.1467-9655.2007.00427.x

Edwards, S., \& Launder, C. (2000). Investigating muscularity concerns in male body image: Development of the Swansea Muscularity Attitudes Questionnaire. International Journal of Eating Disorders, 28, 120-124. doi:10.1002/(SICI) 1098-108X(200007)28:1<120::AID-EAT15>3.0 . $\mathrm{CO} ; 2-\mathrm{H}$

Escoto, M. C., Álvarez, G., Bedolla, G., Velázquez, B., Yáñez, K., \& Mancilla, J. M. (2007, June). Internal consistency and factor structure of Drive for Muscularity Scale (DMS) for undergraduate students. XV Congreso Mexicano de Psicología, Hermosillo, Sonora, Mexico.

Fallon, A. E., \& Rozin, P. (1985). Sex differences in perceptions of desirable body shape. Journal of Abnormal Psychology, 94, 102-105. doi:10.1037/0021-843X.94.1.102

Fontes, O. A. (2009). Gênero, beleza, e consumo: Um estudo exploratório sobre o olhar masculino [Gender, beauty, and consumption: An exploratory study about the male gaze]. Unpublished master's thesis, Universidade federal do Rio de Janeiro, Rio de Janeiro, Brazil.

Fornell, C., \& Larcker, D. (1981). Structural equation models with unobservable variables and measurement error. Journal of Marketing Research, 18, 39-50. doi:10.2307/3151312

Garson, G. D. (2006). PA 765 Statnotes: An online textbook. Retrieved from http://www2.chass.ncsu.edu/garson/pa765/statnote.html

Garver, M. S., \& Mentzer, J. T. (1999). Logistics research methods: Employing structural equation modeling to test for construct validity. Journal of Business Logistics, 20, 33-57.

Giles, D. C., \& Close, J. (2008). Exposure to "lad magazines" and drive for muscularity in dating and non-dating young men. Personality and Individual Differences, 44, 1610-1616. doi:10.1016/j.paid.2008.01.023

Goldenberg, M. (2002). Nu \& vestido [Naked and dressed]. Rio de Janeiro, Brazil: Record.

Gouveia, V. V., Singelis, T. M., \& Coelho, J. A. (2002). Self-construal scale: Corroborations of its factorial structure. Avaliação Psicológica, 1, 49-59. 
Gray, J. J., \& Ginsberg, R. L. (2007). Muscle dissatisfaction: Psychological and cultural research and theory. In K. Thompson \& G. Cafri (Eds.), The muscular ideal: Psychological, social, and medical perspectives (pp. 15-39). Washington, DC: American Psychological Association. doi:10 $.1037 / 11581-001$

Grogan, S., \& Richards, H. (2002). Body image: Focus groups with boys and men. Men and Masculinities, 4, 219-232. doi:10.1177/ 1097184X02004003001

Hair, J. F., Jr., Anderson, R. E., Tatham, R. L., \& Black, W. B. (2009). Multivariate data analysis. Upper Saddle River, NJ: Prentice Hall.

Hatoum, I. J., \& Belle, D. (2004). Mags and abs: Media consumption and bodily concerns in men. Sex Roles, 51, 397-407. doi:10.1023/B:SERS .0000049229 .93256 .48

Herdman, M., Fox-Rushby, J., \& Badia, X. (1998). A model of equivalence in the cultural adaptation of HRQol instruments: The universal approach. Quality of Life Research: An International Journal of Quality of Life Aspects of Treatment, Care, \& Rehabilitation, 7, 323-335. doi:10.1023/A:1008846618880

Heyward, V. H., \& Stolarczyk, L. M. (1996). Applied body composition assessment. Champaign, IL: Human Kinetics.

Iriart, J. A. B., Chaves, J. C., \& Orleans, R. G. (2009). Body cult and use of anabolic steroids by bodybuilders. Caderno de Saúde Pública, 25, 773-782. doi:10.1590/S0102-311X2009000400008

Jöreskog, K., \& Sörbom, D. (1999). Prelis2: User's reference guide. Chicago, IL: Scientific Software International.

Jung, J., Forbes, G. B., \& Chan, P. (2010). Global body and muscle dissatisfaction among college men in the United States and Hong Kong, China. Sex Roles, 63, 104-117. doi:10.1007/s11199-010-9760-z

Karazsia, B. T., \& Crowther, J. H. (2008). Psychological and behavioral correlates of the SATAQ-3 with males. Body Image, 5, 109-115. doi: 10.1016/j.bodyim.2007.08.004

Kelley, C. C. G., Neufeld, J. M., \& Musher-Eizenman, D. R. (2010). Drive for thinness and drive for muscularity: Opposite ends of the continuum or separate constructs? Body Image, 7, 74-77. doi:10.1016/j.bodyim .2009.09.008

Kimmel, S. B., \& Mahalik, J. R. (2004). Measuring masculine body ideal distress: Development of a measure. International Journal of Men's Health, 3, 1-10. doi:10.3149/jmh.0301.1

Latner, J. D., \& Wilson, R. E. (2011). Obesity and body image in adulthood. In T. Cash \& L. Smolak (Eds.), Body image: A handbook of science, practice, and prevention (pp. 189-197). New York, NY: Guilford Press.

Liao, Y., Knoesen, N. P., Castle, D. J., Tang, J., Deng, Y., Bookun, R., . . Liu, T. (2010a). Symptoms of disordered eating, body shape, and mood concerns in male and female Chinese medical students. Comprehensive Psychiatry, 51, 516-523. doi:10.1016/j.comppsych.2009.11.007

Liao, Y., Knoesen, N. P., Deng, Y., Tang, J., Castle, D. H., Bookun, R., . . . Liu, T. (2010b). Body dysmorphic disorder, social anxiety, and depressive symptoms in Chinese medical students. Social Psychiatry and Psychiatric Epidemiology, 45, 963-971. doi:10.1007/s00127-0090139-9

Lilleaas, U. B. (2007). Masculinities, sport, and emotions. Men and Masculinities, 10, 39-53. doi:10.1177/1097184X07299329

Litt, D., \& Dodge, T. (2008). A longitudinal investigation of the Drive for Muscularity Scale: Predicting use of performance enhancing substances and weightlifting among males. Body Image, 5, 346-351. doi:10.1016/ j.bodyim.2008.04.002

Luciano, L. (2001). Looking good: Male body image in modern America. New York, NY: Hill and Wang.

Maruyama, G. M. (1998). Basics of structural equation modeling. Thousand Oaks, CA: Sage publications.

Matsudo, S. M. (2002). Physical activity level of São Paulo State population: An analysis based on gender, age, socio-economic status, demo- graphics and knowledge. Revista Brasileira de Ciências do Movimento, 10, 41-50.

McCreary, D. R. (2007). The Drive for Muscularity Scale: Description, psychometrics, and research findings. In J. K. Thompson \& G. Cafri (Eds.), The muscular ideal: Psychological, social, and medical perspectives (pp. 87-106). Washington, DC: American Psychological Association. doi:10.1037/11581-004

McCreary, D. R. (2011). Body image and muscularity. In T. Cash \& L. Smolak (Eds.), Body image: A handbook of science, practice, and prevention (pp. 198-205). New York, NY: Guilford Press.

McCreary, D. R., \& Sasse, D. K. (2000). An exploration of the drive for muscularity in adolescent boys and girls. Journal of American College Health, 48 , 297-304. doi:10.1080/07448480009596271

McCreary, D. R., Sasse, D. K., Saucier, D. M., \& Dorsch, K. D. (2004). Measuring the drive for muscularity: Factorial validity of the Drive for Muscularity Scale in men and women. Psychology of Men \& Masculinity, 5, 49-58. doi:10.1037/1524-9220.5.1.49

McCreary, D. R., \& Saucier, D. M. (2009). Drive for muscularity, body comparison, and social physique anxiety in men and women. Body Image, 6, 24-30. doi:10.1016/j.bodyim.2008.09.002

McCreary, D. R., Saucier, D. M., \& Courtenay, W. H. (2005). The drive for muscularity and masculinity: Testing the associations among genderrole traits, behaviors, attitudes, and conflict. Psychology of Men \& Masculinity, 6, 83-94. doi:10.1037/1524-9220.6.2.83

McPherson, K. E., McCarthy, P., McCreary, D. R., \& McMillan, S. (2010). Psychometric evaluation of the Drive for Muscularity Scale in a community-based sample of Scottish men participating in an organized sports event. Body Image, 7, 368-371. doi:10.1016/j.bodyim.2010.06 .001

Mickalide, A. D. (1990). Sociocultural factor influencing weight among males. In A. E. Andersen (Ed.), Males with eating disorders (pp. 30-39). London, UK: Brunner-Routledge.

Morrison, T. G., \& Morrison, M. A. (2006). Psychometrics properties of the Swansea Muscularity Attitudes Questionnaire (SMAQ). Body Image, 3, 131-144. doi:10.1016/j.bodyim.2006.03.005

Morrison, T. G., Morrison, M. A., \& Hopkins, C. (2003). Striving for bodily perfection? An exploration of the drive for muscularity in Canadian men. Psychology of Men \& Masculinity, 4, 111-120. doi:10.1037/ 1524-9220.4.2.111

Morrison, T. G., Morrison, M. A., Hopkins, C., \& Rowan, E. T. (2004). Muscle mania: Development of a new scale examining the drive for muscularity in Canadian males. Psychology of Men \& Masculinity, 5, 30-39. doi:10.1037/1524-9220.5.1.30

Morrison, T. G., Morrison, M. A., \& McCann, L. (2006). Striving for bodily perfection? An overview of the drive for muscularity. In. M Kindes (Ed.), Body image: New research (pp. 1-34). Columbus, NY: Nova Science.

Nowell, C., \& Ricciardelli, L. A. (2008). Appearance-based comments, body dissatisfaction, and drive for muscularity in males. Body Image, 5, 337-345. doi:10.1016/j.bodyim.2008.06.002

Olivardia, R. (2001). "Mirror, mirror on the wall, who's the largest of them all?" The features and phenomenology of muscle dysmorphia. Harvard Review of Psychiatry, 9, 254-259.

Pedhazur, E. J. (1997). Multiple regression in behavioral research: Explanations and predictions. Forth Worth, TX: Harcourt Brace.

Pickett, T. C., \& Cash, T. F. (2005). Men, muscles, and body image: Comparisons of competitive bodybuilders, weight trainers, and athletically active controls. British Journal of Sports Medicine, 39, 217-222. doi:10.1136/bjsm.2004.012013

Pope, C. G., Pope, H. G., Menard, W., Fay, C., Olivardia, R., \& Phillips, K. A. (2005). Clinical features of muscle dysmorphia among males with body dysmorphic disorder. Body Image, 2, 395-400. doi:10.1016/j bodyim.2005.09.001 
Pope, H. G., Phillips, K. A., \& Olivardia, R. (2000). The Adonis complex. New York, NY: Free Press.

Ridgeway, R. T., \& Tylka, T. L. (2005). College men's perceptions of the ideal body composition and shape. Psychology of Men \& Masculinity, 6 , 209-220. doi:10.1037/1524-9220.6.3.209

Ruiz, E. J. C., de Leon, M. C. E. P., Garrido, C. M. C., \& Castillo, R. D. (2010). Anthropometric correlates of muscle obsession. Mexican Journal of Eating Disorders, 1, 125-131.

Ryan, T. A., \& Morrison, T. G. (2009). Factors perceived to influence young Irish men's body image investment: A qualitative investigation. International Journal of Men's Health, 8, 213-234. doi:10.3149/jmh .0803 .213

Sabino, C. (2000). Musculação: Expansão e manutenção da masculinidade [Weight lifting: Expansion and maintenance of masculinity]. In M. Goldenberg (Ed.), Os novos desejos: Das academias de musculação às agências de encontros [The new desires: From gyms to dating agencies] (pp. 61-104). Rio de Janeiro, Brazil: Record.

Schumacker, R. E., \& Lomax, R. G. (2004). A beginner's guide to structural equation modeling. Upper Saddle River, NJ: Lawrence Erlbaum Associates.

Silva, I. S. M. F., \& Moreau, R. L. M. (2003). Use of anabolic-androgenic steroids among body builders in major gym centers in São Paulo, Brazil. Revista Brasileira de Ciências Farmacêuticas, 39, 327-333. doi: 10.1590/S1516-93322003000300012

Silvia, E. S. M., \& Maccallum, R. C. (1988). Some factors affecting the success of specification searches in covariance structure modeling. Mutlivariate Behavioral Research, 23, 297-326. doi:10.1207/ s15327906mbr2303_2

Stanford, J. N., \& McCabe, M. P. (2002). Body Image ideal among males and females: Sociocultural influences and focus on different body parts. Journal of Health Psychology, 7, 675-684. doi:10.1177/ 1359105302007006871

Swami, V., Campana, A. N. N. B. C., Ferreira, L., Barret, S., Harris, A. S., \& Tavares, M. C. G. C. F. (2011). The Acceptance of Cosmetic Surgery Scale: Initial examination of its factor structure and correlates among Brazilian adults. Body Image, 8, 179-185.

Swami, V., \& Chamorro-Premuzic, T. (2008). Factor structure of the Body Appreciation Scale among Malaysian women. Body Image, 5, 409-413. doi:10.1016/j.bodyim.2008.04.005

Swami, V., Hwang, C. S., \& Jung, J. (2012). An examination of the factor structure and correlates of acceptance of cosmetic surgery among South Korean university students. Aesthetic Surgery Journal, 32, 220-229. doi:10.1177/ 1090820X11431577
Swami, V., \& Jaafar, J. L. (in press). Factor structure of the Body Appreciation Scale among Indonesian women and men: Further evidence of a two-factor solution in a non-Western population. Body Image.

Swami, V., Kannan, K., \& Furnham, A. (in press). Positive body image: Inter-ethnic and rural-urban differences among an indigenous sample from Malaysian Borneo. International Journal of Social Psychiatry.

Swami, V., Stieger, S., Haubner, T., \& Voracek, M. (2008). Translation and validation of the German Body Appreciation Scale. Body Image, 5, 122-127. doi:10.1016/j.bodyim.2007.10.002

Swami, V., \& Tovée, M. J. (2005). Male physical attractiveness in Britain and Malaysia: A cross-cultural study. Body Image, 2, 383-393. doi 10.1016/j.bodyim.2005.08.001

Swami, V., \& Voracek, M. (in press). Men's sexist attitudes and objectification of women are associated with their own drive for muscularity. Psychology of Men and Masculinity.

Tager, D., Good, G. E., \& Morrison, J. B. (2006). Our bodies, ourselves revisited: Male body image and psychological well-being. International Journal of Men's Health, 5, 228-237. doi:10.3149/jmh.0503.228

Thompson, J. K. (1990). Body image disturbance: Assessment and treatment. New York, NY: Pergamon Press.

Thompson, J. K. (2004). The (mis) measurement of Body Image: Ten strategies to improve assessment for applied and research purposes. Body Image, 1, 7-14. doi:10.1016/S1740-1445(03)00004-4

Thompson, J. K., \& Cafri, G. (Eds.). (2007). The muscular ideal: Psychological, social and medical perspectives. Washington, DC: American Psychological Association. doi:10.1037/11581-000

Tylka, T. L., Bergeron, D., \& Schwartz, J. P. (2005). Development and psychometric evaluation of the Male Body Attitudes Scale (MBAS) Body Image, 2, 161-175. doi:10.1016/j.bodyim.2005.03.001

Vartanian, L. R., Giant, C. L., \& Passino, R. M. (2001). Ally McBeal vs. Arnold Schwarzenegger: Comparing mass media, interpersonal feedback and gender as preditcorts of satisfaction with body thinness and muscularity. Social Behaviour and Personality, 29, 711-723. doi: 10.2224/sbp.2001.29.7.711

Watkins, D. (1989). The role of confirmatory factor analysis in crosscultural research. International Journal of Psychology, 24, 685-701.

Wojtowicz, A. E., \& von Ranson, K. M. (2006). Psychometric evaluation of two scales examining muscularity concerns in men and women. Psychology of Men \& Masculinity, 7, 56-66. doi:10.1037/1524-9220.7 .1 .56

Received February 3, 2012

Revision received August 6, 2012

Accepted August 11, 2012 